Twisting Arms and Holding Hands: M.A. Students and Conference Participation

\author{
Jeffrey J. Ryan and Marijke Breuning, University of Arkansas
}

\begin{abstract}
As they start their graduate education, students tend to perceive themselves more as absorbers than as producers of knowledge. While there is much they will need to absorb in substance, theory, and methodology, this is also an appropriate time to start thinking of making contributions to the discipline. This transition is especially important for students in Ph.D. programs, but we argue that M.A. programs can play an important role in introducing students to the profession.
\end{abstract}

One aspect of an introduction to the profession is to encourage students to participate in conferences. While Ph.D. students participate with some regularity, M.A. students in political science generally are not professionally active. We therefore invited some of our M.A. students to present papers at the annual conference of our state's political science association.

This forum seemed to strike a good balance: it gave the students a chance to experience a "real life" conference without the full-scale terror they might have felt at a national conference. This exercise in professional socialization may be of interest to Ph.D. students and junior faculty in addition to the master's students who are the target of our efforts.

\section{Turning Students Into Political Scientists}

The first step, of course, was identifying candidates for our experimental project. The pool of students that could be targeted for conference participation is of course bounded by the number enrolled in the M.A. program who meet the basic criteria. More important, however, are considerations of faculty time and support. Although one of us had wanted to involve students in the state confer- ence for some years, it became a reality only when another faculty member expressed an interest in making it a team effort. This way we could share the work involved and support each other in what for us was an extracurricular activity.

After identifying a pool of five solid student candidates, we contacted the conference organizers and arranged the student proposals into two panels. We each chaired one panel, and one of us participated with a paper as well. The conference organizers helped locate discussants and added additional papers to the panels. Because the state association is fairly small and each field is represented with only a few panels, this approach made sense. The real work of guiding the students through the process had hardly begun at this stage.

Two important elements of the guidance we gave the students as they prepared for their first conference were critiquing drafts of their papers and scheduling a practice presentation. However, the mentoring role extended in many ways beyond these activities.

The initial draft of each student's paper was completed as part of a seminar. Because we knew the student would be revising the paper, we provided more extensive comments than we might have otherwise. We then asked the students to complete a second draft about a month prior to the conference. Although we hoped that this draft would need only minor revisions, we wanted to build in time for the students to do further work on their papers prior to mailing them to the discussants.

At this point, the process reached a critical juncture as the full terror of the endeavor began to dawn on the students. Confronted at last with the realization that they would, in fact, have to present these papers to an audience of real political scientists, the students suddenly found their work to be littered with incurable problems. There was a tendency, paradoxically most prevalent among those whose work was strongest, to rewrite the entire paper from scratch. With a delicate combination of cajoling, coercion, and cold logic ("Do you really think you'll be able to write another entire paper in 48 hours?'”), we were able to convince them that correcting flaws in their work was wiser than abandoning it altogether.

As the conference date came closer, the students became more and more apprehensive. To give them a better idea of what would happen, we scheduled an afternoon session at which they each were to give a fifteen-minute presentation of their work, while we served as discussants. In addition to reducing the anxiety, this provided an opportunity to give feedback about the content of the presentations. We both had read the papers prior to these initial presentations and used this knowledge to make suggestions for any needed changes of emphasis. By including in this practice session the paper to be delivered by the faculty member, we gave the students a feel for "interpeer" criticism ("they're not just picking on us, they grill each other just as badly'). This enhanced the students' emerging image of being comrades in a shared intellectual enterprise.

The students also learned more tangible things, such as how much information can be presented in fifteen minutes and how to convey the essence of their research in a limited time frame. We furthermore stressed that they should not be reading from their papers, even though this is often done at conferences. The students found practicing their presentations useful, and several of them got together at another time to practice. This second time, they used a video camera to 
tape themselves. The unforgiving eye of the camera taught them much about how the audience would perceive them. Such brutal treatment in preparation for a first conference presentation is warranted only if the students themselves initiate it, because it has the potential of making them more, rather than less, self-conscious. However, it can be a useful tool.

At the conference the students suffered stage fright, with the anxieties that had plagued them earlier all flooding back at once. Despite some nervousness in their voices, they all managed coherent presentations. By the time they reacted to audience questions, the nervousness had gone. The audience was taking their work seriously and asking them questions as peers, which probably more than anything else, helped the students to perceive themselves as professionals. After all, these were exactly the people whose reactions they had feared: real professors whom they did not know and whom they were afraid would see them as little leaguers trying to play ball with professionals.

The reactions we got later from our colleagues across the state as well as at our own institution were favorable. Those at other schools generally commented on the quality of the papers, while our departmental colleagues saw it as something that enhanced our program.

\section{Twisting Arms: Making the Selection}

In choosing the "unlucky few" who will be asked to participate, three characteristics are important: strong minds, strong backs, and a degree of independence. This determines whether the students have the ability to write a paper worthy of a conference, the ability to meet deadlines, and the ability to rely on their own judgment-lest you want to spend every waking moment walking the students through their papers. Students who possess all three of these are the exception rather than the norm. The brightest students are not necessarily the best at finishing their work on time, and the most diligent do not always produce paradigm-shattering papers. Seek those whom you expect will produce a reasonably good paper, roughly on time, with a modicum of independence. The time invested in choosing participants carefully will pay off in the long run.

Additionally, it is important to balance a focus on the most promising students with the clear message that although conference participation can enhance their education, it is an extracurricular activity.

Once you have selected a pool of participants, the next step is making a deal they cannot refuse. It is necessary to make clear to them that there are tangible, significant benefits to putting themselves through such a seemingly masochistic ordeal. Through a skillful combination of flattery ("We really think you'd make a valuable contribution to the field by presenting this paper"), veiled threats ("It's an awfully competitive process when you apply for a doctoral program, and every little bit helps"'), and, if necessary, outright bribery ("Did we mention there's a $\$ 50$ prize for the Best Student Paper?'), students can be persuaded to agree. In our experience, convincing students to participate was less a matter of persuading them to commit to the extra work involved than a matter of assuring them they were qualified to present a paper at a professional conference. It was the first step in a process of ego bolstering that continued right through the actual presentations.

We organized papers into panels in consultation with the conference organizers. That is not the only way to go, however. It may be reasonable to ask students to submit individual proposals. Since such individual proposals may not find a place on the program, it is probably wise to indicate this possibility to the students. In any case, it still makes sense to review the proposal and perhaps ask the student to rewrite it. This makes the abstract the first in a series of learning experiences that surround first-time conference participation. And it provides you with a bit of quality control.

\section{Holding Hands: Minimizing the Terror}

Just as in the old joke about the violinist who asked how to get to Carnegie Hall, the key here is practice, practice, practice. The more familiar the students are with all facets of the conference process, the less apprehensive they will be when their date with destiny arrives. Practice panels are invaluable in this regard, giving students a chance to get used to speaking in front of an audience, timing their presentations, and receiving comments and criticisms. Though we conducted these panels outside of class, it would also be possible to mimic such presentations in a seminar setting, by assigning students to the various roles of panel participants and requiring them to submit their papers to their classmates who play the role of discussants.

Another way to lessen the apprehension among the students is to make them realize that their fears are natural and that, contrary to their popular perceptions, political scientists do not spring forth from Zeus's brow with a conference paper ready for presentation in their hands. It really helps them to know about your first time, about how the bulb on your overhead projector failed, or you went to the wrong room, or the entire panel failed to show up. Better yet, tell them about the time you saw the eminent Professor $\mathbf{X}$ deliver a stern and somber presentation without realizing that there was an enormous ketchup stain on the front of his jacket. Make them realize that we are, after all, mortals like them.

A final suggestion would be to encourage camaraderie. Misery does indeed love company. Creating a legion of "death march survivors" generates both solidarity and a support network. Interaction within the group gives the students a good idea of an often overlooked aspect of the research process, namely, that even though only one author's name eventually appears on a paper or article, the end product is always enriched with the comments and criticisms of colleagues, discussants, and review- 
ers. It also breaks down feelings of isolation and doubt that can increase anxiety and undermine confidence.

\section{Student Benefits}

One of the more difficult things to teach students is how exactly research is done. Too often, they have an image of the process that borders on alchemy, with the Ph.D. serving as a sort of portal through which delivered truths travel. Participating from beginning to end, students learn that academics are not mythical beings conveying unsullied wisdom from a political science Valhalla. The process of conducting research entails a good deal more "muddling through" than divine revelation. As students observe and experience that firsthand, their capacity and willingness to look critically at the work of professionals will be bolstered.

Another valuable lesson students will likely take away from the conference is that discipline is as important as intellect when it comes to research. Meeting deadlines is critical, and getting into the habit of doing so outside the classroom setting is an important exercise in professional responsibility. In all likelihood, students will get a taste of how failing to meet these responsibilities entails costs. At a personal level, they will realize how irritating it is to be asked to discuss a fellow panelist's work if that panelist hands the paper to them only minutes before the panel starts. On a professional level, they will likely pick up on the collective ostracism of those who fail to follow guidelines of professional courtesy.

The point at which a student says, "I could have done that," is the point at which they cross the line from consumers to participants. This is a crucial first step to becoming a political scientist and is especially important for those on the doctoral track. For students who do not envision themselves completing a Ph.D., conference participation may still be beneficial. It requires students to practice presentation skills to achieve a concise and cogent verbalization of their ideas. Students mentioned that it also entailed learning to accept and deal with criticism of one's work. Of course, students present their work for criticism every time they submit a term paper, but there is something qualitatively different about speaking to an audience at least partially made up of strangers and listening to a critique of one's work in that setting. These skills have applicability beyond academia; criticism of one's ideas and efforts must be faced in just about any line of work. Furthermore, at a personal level, the experience enhances self-esteem.

\section{As students observe and experience that firsthand, their capacity and willingness to look critically at the work of professionals will be bolstered.}

Placing M.A. students in Ph.D. programs can be very difficult for a variety of reasons. Any advantage in this competition can be useful, and delivering a paper at a conference gives a good indication that the student is serious about becoming an active member of the discipline-both to the faculty at the M.A. institution and to those deciding on the admission of a student to their Ph.D. program. Participation in conferences by students in terminal M.A. programs is extraordinarily limited in political science and thus serves to set students who do participate apart from the pack. We should not delude ourselves into thinking that such participation will make the application process substantially easier-students will have to meet the basic criteria of the programs they apply to-but as an addition to basic qualifications it could hardly hurt an applicant's chances.

\section{Departmental Benefits}

The students are not the only ones to gain. The department benefits in several ways from students who are beginning to see themselves as participants in the discipline. We found that the graduate students increasingly came to see each other as resources rather than merely fellow classmates. They began to discuss their interpretations of the literature with each other, to regard each other as sounding boards for ideas that they were not quite ready to have scrutinized by faculty, and to ask each other for feedback on drafts. In other words, in the process of preparing to go to their first conference these students altered-and, in our opinion, much improved-the intellectual climate among themselves.

Secondly, the interaction between the students and faculty changed as well. We started to get questions about what we thought of this or that interpretation of a theory, or sometimes the student's own understanding of that theory. Rather than waiting for exam time to find out whether they had "gotten it right," they began to understand that there was not always a clear right or wrong. The dialogue resulted in a more active attitude towards learning on the part of the students, which made it more fun to work with them. Both these changes in the interactions among the students themselves and those between the students and faculty added up to positive changes in the cohesion and intellectual climate of the department.

Furthermore, the students' conference participation gave the faculty of other colleges around the state a glimpse at the education students receive in our M.A. program. They were impressed with the performance of our students. This is important, because these faculty members will advise their undergraduates as they start considering options for further study.

\section{Potential Problems}

A very real potential problem is the creation of a two-class system 
within the graduate student population. Possibly, those students not recruited will feel left out and inferior, generating resentment. This should not become an excuse for including students who, for whatever reason, will not produce a conference-worthy paper or who will only do so at an inordinately great cost to the faculty. Those who do not present could be given a role by inviting them to come along as observers, and perhaps they could help by reading and critiquing drafts.

Conference participation is and remains an extracurricular activity. The problem of creating division among the student body is probably greatest when the idea of participating in conferences is first introduced. It is more likely to be initiated by the faculty - as in our case-and students may perceive inclusion or exclusion as a judgment on their abilities. Tact and diplomacy on the part of the faculty are probably the best avenues to guard against negative fall-out. As the student culture changes and conference participation becomes more of a student-initiated activity, this is likely to become less of an issue.

The investment of time and energy on the part of faculty involved is significant. If the usefulness of encouraging M.A. student participation in conferences is not recognized by the department, or if it is recognized but tangible support is not forthcoming, faculty may be tempted to forego the whole endeavor. However, nothing convinces like success. If we had asked other faculty members in our department to join us in our first effort, they may well have excused themselves with reference to their own, very full, research agendas. Now that they have seen our M.A. students in action, several other faculty members have expressed an interest in becoming involved in this exercise, which one of them termed a "pilot project." Starting off with a small core of carefully selected students can help to assuage concerns among colleagues about committing substantial time to an uncertain endeavor.

\section{Conclusions}

Despite all the anxieties during the time leading up to the conference, the students found the experience worthwhile. So did we. Although it had taken some arm twisting to get them to commit to participating and although the hand holding took more of our time than we had envisioned, the end result was a set of solid papers and coherent presentations. The students received positive feedback at the conference. In the months after the conference, they made comments about how scared they had been, but also about the confidence they had gained. They all said they would do it again, and three students currently are writing papers for their second conference.
As this group starts talking with the new students entering our program, their experiences will help a new generation of students decide to participate. The initial group will be able to help us address some of the anxieties the first group had with war stories all their own.

In sum, involving M.A. students in state or regional conferences provides them with an invaluable learning experience about the profession, while it simultaneously enhances the intellectual climate of the department. Although M.A. programs serve a variety of purposes, one of those is to help students make well-informed decisions about further study. Conference participation alone will not achieve that but, in the process of gaining a better understanding of what life as an academic entails, it should be helpful as a piece of the decisionmaking puzzle.

\section{About the Authors \\ Jeffrey J. Ryan is an assistant professor in the Department of Political Science at the University of Arkansas, where he teaches comparative politics. His research primarily concerns democratization and violence in Latin America. \\ Marijke Breuning is an assistant professor in the Department of Political Science at the University of Arkansas. She teaches interna- tional relations. Her research focuses on psychological approaches to the study of foreign policy.}

\title{
Giving Flesh to Ideas: Constructing a Cultural Dialogue
}

\author{
Dean C. Hammer, Memphis State University
}

There is perhaps nothing more unsatisfying-for student or teacherthan the perfunctory term paper performed with formulaic diligence. The term paper is assigned to encourage a competent, if not critical discussion, of a particular topic through multisource research. Truth be told, students have neither mastered nor exhausted this form. They have, though, grown tired of it, with the result that the unengaged student is left still unengaged.

The challenge is to get students excited about the course material without sacrificing the competent scholarship encouraged by the term paper. What follows is one approach I used in an American polit- ical culture class. The course was the third of a year-long sequence in American culture that first-year students could take. The paper was a capstone to synthesize the previous two courses in English and history, though it would work for a standalone course. The assignment was developed in conjunction with David Crowe, an English professor 